\title{
Influence of Concrete Mix Proportions and Curing Regimes on Density, Absorption, and Voids in Hardened Concrete
}

\author{
Omer Mohammad Abdul kreem \\ Civil Engineering Department - College of Engineering
}

\section{Abstract}

The aim of this research is to assess the mechanical strength and durability performance of the concrete incorporating various contents of the ordinary Portland cement and w/c. Besides, it has been undertaken to study the effect of curing methods on compressive strength of the concrete as well as the physical properties, which are investigated in terms of density, absorption and volume of permeable voids as an (porosity). Many researchers consider these physical properties as an indicating signs on the permeability of the concrete, or in other words, they were as an indirect method to measure the permeability and to evaluate it.

Five mixes are prepared and tested at the age of 28 days. The concrete specimens are cured in two different methods, in the first method specimens are moist cured while in the second method the specimens are air cured at $20{ }^{\circ} \mathrm{C}$ and $80 \%$ relative humidity to examine the effect of curing regimes. An experimental procedure for testing the physical properties of concrete is carried out according to ASTM (C 642-97). The results of the study showed that the increase of cement content and the reduction in the w/c leads to more durable concrete because of loss of absorption and porosity characteristics, in addition to that, higher density and compressive strength. Test results also showed that the water curing method have significant effect for improving the strength and durability performance of the concrete.

Keywords: Concrete, Mix Proportion, Curing Conditions, Durability Performance, Physical Properties.

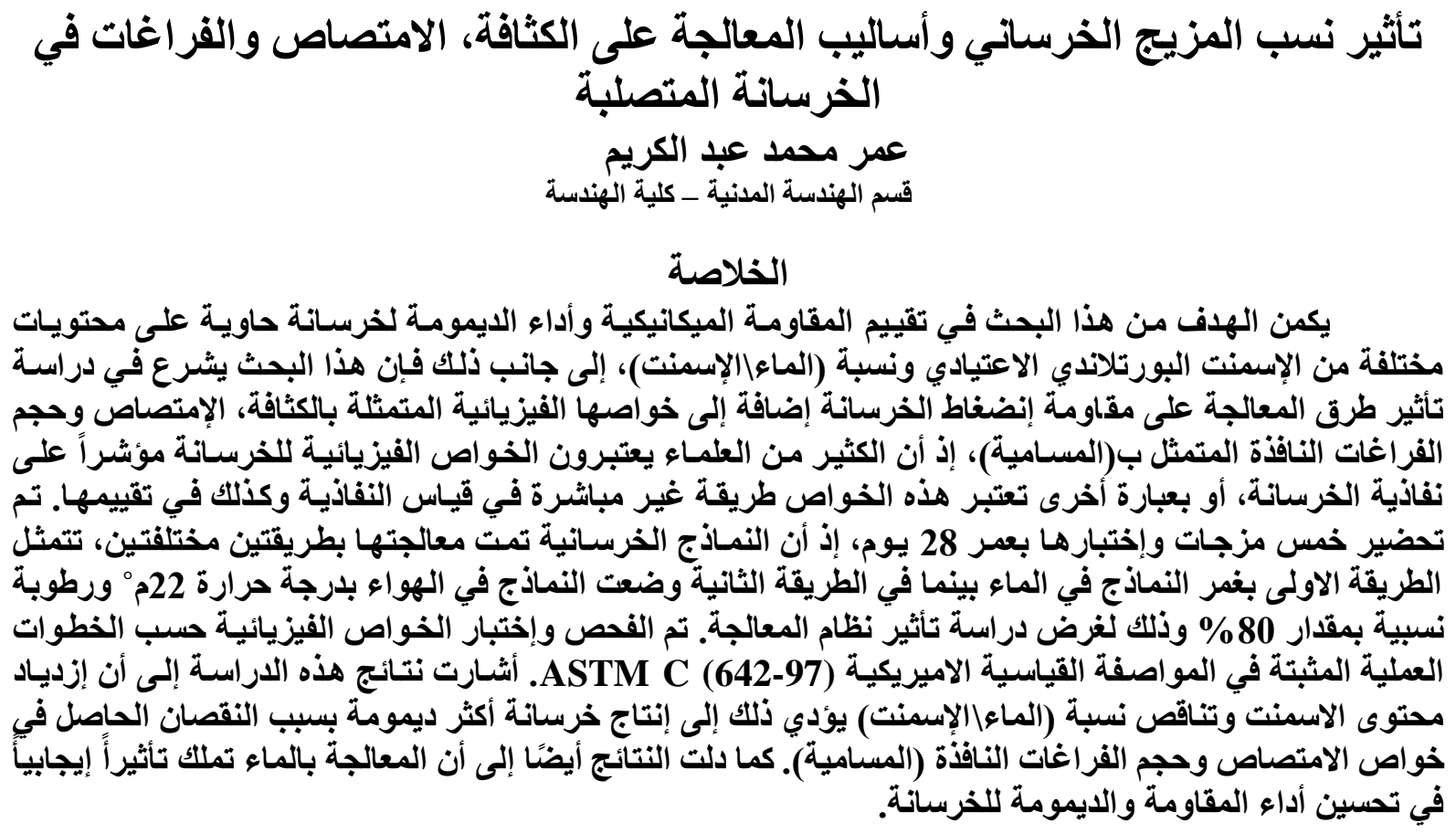




\section{Introduction}

Permeability is an important factor that largely affects the durability of hardened concrete. Permeable concrete allows water and chemicals to penetrate, which, in turn, reduces the resistance of the concrete structure to frost, alkali-aggregate reactivity, and other chemical attacks. Water that permeates into reinforced concrete causes corrosion of steel rebars. Furthermore, impervious concrete is a prerequisite in watertight structures, such as tanks and dams [1].

Permeability tests of concrete are of value, (1) To determine the rate of leakage through the walls of a structure such as a concrete pipe. (2) To determine the effects of variations in the cement and aggregates, or the effects of various operations in mixing, placing, and curing. (3) To estimate the relative durability and life of concrete as affected by the corrosive action of percolating waters. (4) To determine basic information on the internal pore structure of concrete, which is related directly to such items as absorption, capillarity, resistance to freezing and thawing, shrinkage, etc.. and (5) To compare the efficiencies of waterproofing materials [2]?

These tests are classified as direct and indirect methods of determining permeability. Various absorption methods, including ASTM (C 642), are used. Direct water permeability data can be obtained by using the Army Corp of Engineers CRC (C 163-92) test method for water permeability of concrete using a triaxial cell. A test method recommended by the American Petroleum Institute for determining the permeability of rock is also available [3].

A number of absorption-related properties are used to indicate the porosity and durability potential of concrete. Absorption, initial surface absorption (ISAT), prostivity, and apparent volume of permeable void (AVPV) are each fundamentally a measure of capillary absorption or absorption rate of concrete [4].

The absorption tests have been standardized in many countries (for example, in Great Britain: BS 1881 Test for Determining the Initial Surface Absorption of Concrete. In North America: ASTM Test Method for Specific Gravity, Absorption, and Voids in Hardened Concrete, (C 642), ASTM Test Method for Evaluating the Effectiveness of Materials for Curing Concrete, (C 1151), and ASTM Test Method for Measurement the Rate of Absorption of Water by Hydraulic Cement Concretes, (C 1585). In addition, in Australia: AS1342); however, the differences in the test limits and procedures create considerable variation in sorptivity measurements [5].

Generally, concrete properties and durability are influenced by curing condition, which greatly affects the hydration of cement [6]. Curing prevents the loss of moisture from the concrete surface (especially in a hot, windy, or dry weather condition), supplies the necessary moisture, and maintains a favorable concrete temperature for a sufficient period of time so that the surface develops adequate durability by reducing the porosity by the necessary hydration of cement particles at the surface. Therefore, curing has a significant influence on the scaling resistance of surface, especially in the presence of deicing chemicals. Durability of a good quality, properly placed, and finished concrete cannot be ensured unless it is adequately cured [7].

To examine the durability performance, the physical characteristics of concrete (density, absorption, and volume of permeable voids as porosity) are employed. In this paper, the objectives of this study were to investigate the effect of different mix proportions of concrete (cement content and w/c) as well as the curing conditions (moist cured and air cured), on the mentioned physical properties mainly, besides the compressive strength. 


\section{Physical Characteristics of Concrete}

Physical tests on concrete can be divided into three basic types [8]:

1. Tests to determine strength (compressive / tensile);

2. Determination of density and excess voidage;

3. Tests to assess pore structure (absorption / permeability).

\subsection{Bulk Density}

is the mass per unit volume of the material. It can be used together with moisture content and specific gravity to calculate a stabilized/solidified (S/S) material porosity and degree of saturation. These properties are related to durability and leach ability, although the relationship is not simple. It can also be used to assess the homogeneity of the (S/S) material. Bulk density can also be used together with mass change factor to calculate volume increase due to treatment [9].

\subsection{Specific Gravity}

is a measure of the solid density of a material relative to the density of water. This property is generally needed to calculate other physical properties [9].

\subsection{Absorption}

is a measure of multi-dimensional capillary absorption of water into concrete. The amount of water absorption of a concrete depends on the porosity and its interconnectivity, the moisture condition or degrees of internal drying and the temperature of the water [4].

The absorption is considered to be related to the resistance of concrete to weathering, since if no water entered its pores, there would be little or no disintegration caused by freezing or thawing or by aggressive waters. However, actual tests show no reliable correlation of total absorption with durability of concrete, but some correlation appears to exists between the rate of absorption and durability [2].

Most concrete is only partly saturated and the initial ingress of water and dissolved salts is dominated, at least initially, by capillary absorption rather than either water permeability or ion diffusion. Wide varieties of water absorption tests on concrete have been developed. These tests measure the weight gain of a sample, volume of water entering the sample, depth of penetration, or a combination thereof, by either complete immersion of dry samples in water, exposing only one face to water, or spraying the specimen surface with water. Absorption is measured either at a single, arbitrary time or by measuring the rate of absorption (by change in mass). Although in all these tests the absorption process is proportional to the square root of time over a specified time, the positivity varies a great deal between test methods [5].

\subsection{Volume of Permeable Voids (Porosity)}

The volume of permeable voids (VPV) is an important property of concrete as it affects the transport mechanisms through the concrete such as ingress of aggressive liquids and gases. Conventional normal weight concretes have (VPV) values of about (12\%-16\%) [10]. The ASTM (C 642) method measures the volume of permeable voids (VPV) as a percentage of the volume of the solid. The Australian Standard (AS 1012.21) test method has been adapted from the ASTM method. It measures the apparent volume of permeable voids (AVPV) as a percentage of the volume of the bulk materials, i.e. solid and voids [4]. 
There is no doubt that porosity defined as the total volume of the overall volume of pores larger than gel pores, expressed, as a percentage of the overall volume of the hydrated cement paste, is a primary factor influencing the strength of the cement paste [11].

Porosity is one of the major parameters, which influence the strength, and durability of concrete. The porosity of a porous material, such as cement paste, mortar, concrete and other porous material can be determined by measuring any of two quantities; bulk volume, pore volume or solid volume. The porosity is the fraction of the bulk volume of the material occupied by voids [12].

The durability of concrete is related to the evolution of its porous network. The porosity of the concrete affects its mechanical strength but also its transfer properties. High porosity is detrimental to the strength and permeability of a concrete, particularly if the pores are of large diameter and connected [13].

The porosity of concrete is largely developed during the setting period. Settlement of the solid particles causes the water to rise and form many water channels. Some of the water is trapped below the aggregate particles, and some fills the fine interstices among the cement particles. Hydration of the cement produces a gel which decreases the size of these water voids and increases the water tightness of the concrete but the voids are never eliminated [2].

\section{Experimental Program}

This part deals with the various materials used in the present investigation, their choice, grading and relevant properties. It also discusses the tests performed and the selected specifications for the experimental part of the research.

\subsection{Materials}

The materials used throughout this research were locally available materials. They included cement, fine aggregate, and coarse aggregate, with no additives used.

\subsubsection{Cement}

A local manufactured cement known as "Badoosh Tawsee" brand from Badoosh cement factory is used during this study. The cement complies with Iraqi specifications (IQS, No.5, 1984). The physical and chemical properties are given in tables (1) and (2) respectively.

Table (1): Physical Properties of the Cement Used

\begin{tabular}{|c|c|c|}
\hline & Test Result & Standard (IQS, No.5, 1984) \\
\hline Fineness (Residue on sieve No.170) & $7 \%$ & $10 \%(\max )$ \\
\hline Initial setting time (min.) & 150 & 60 (min) \\
\hline Final setting time (min.) & 270 & $600(\max )$ \\
\hline Specific gravity & 3.14 & \\
\hline Compressive strength (MPa): & & 16.0 \\
at 3days & 23.1 & 24.0 \\
at 7days & 26.9 & \\
\hline
\end{tabular}


Abdul Kreem: Influence of Concrete Mix Proportions and Curing Regimes on Density,

Table (2): Chemical Properties of the Cement Used

\begin{tabular}{|c|c|c|c|c|c|}
\hline $\begin{array}{c}\text { Chemical } \\
\text { Composition }\end{array}$ & $\begin{array}{c}\text { Value } \\
(\%)\end{array}$ & $\begin{array}{c}\text { Standard (IQS, } \\
\text { No.5, 1984) }(\%)\end{array}$ & $\begin{array}{c}\text { Chemical } \\
\text { Composition }\end{array}$ & $\begin{array}{c}\text { Value } \\
(\%)\end{array}$ & $\begin{array}{c}\text { Standard (IQS, } \\
\text { No.5, 1984) (\%) }\end{array}$ \\
\hline $\mathrm{SiO}_{2}$ & 24.30 & ---- & $\mathrm{C}_{3} \mathrm{~A}$ & 8.25 & Min. 5 \\
\hline $\mathrm{AL}_{2} \mathrm{O}_{3}$ & 5.22 & ---- & $\mathrm{C}_{4} \mathrm{AF}$ & 10.02 & ---- \\
\hline $\mathrm{Fe}_{2} \mathrm{O}_{3}$ & 3.29 & ---- & Solid Solution & 16.56 & ---- \\
\hline $\mathrm{MgO}^{\mathrm{SO}}$ & 5.91 & Max. 4 & Free Lime & 0.87 & ---- \\
\hline $\mathrm{SO}_{3}$ & 2.25 & Max. 3 & Loss on Ignition & 1.78 & ---- \\
\hline $\mathrm{C}_{3} \mathrm{~S}$ & 30.80 & ---- & Insoluble Residue & 0.3 & Max. 1.5 \\
\hline $\mathrm{C}_{2} \mathrm{~S}$ & 46.44 & ---- & & & \\
\hline
\end{tabular}

\subsubsection{Mixing Water}

Ordinary drinking (tap) water was used for mixing the concrete.

\subsubsection{Fine Aggregate}

Coarse sand in accordance with (BS 882 : 1983) was used in this investigation, normally available in the "Kanhash" area. Its main properties are listed in table (3).

Table (3): Sieve Analysis of Fine Aggregate

\begin{tabular}{|c|c|c|c|c|c|}
\hline \multirow{3}{*}{$\begin{array}{l}\text { Sieve } \\
\text { Size } \\
(\mathrm{mm})\end{array}$} & \multicolumn{5}{|c|}{$\%$ Passing on each Sieve } \\
\hline & \multirow{2}{*}{$\begin{array}{c}(\mathrm{O} / \mathrm{A}) \\
\text { Specification } \\
\text { Limits }\end{array}$} & \multirow{2}{*}{$\begin{array}{l}\% \text { Passing of } \\
\text { the Sample }\end{array}$} & \multicolumn{3}{|c|}{ Additional Limits } \\
\hline & & & Coarse $(\mathrm{C})$ & Medium (M) & Fine $(F)$ \\
\hline 4.76 & 100 & 95 & - & - & - \\
\hline 2.36 & $89-100$ & 81.2 & - & - & - \\
\hline 1.18 & $60-100$ & 67.2 & $60-100$ & $65-100$ & $80-100$ \\
\hline 0.6 & $30-100$ & 47.9 & $30-90$ & $45-100$ & $70-100$ \\
\hline 0.3 & $15-100$ & 20.8 & $15-54$ & $25-80$ & $55-100$ \\
\hline 0.15 & $5-70$ & 6.6 & $5-40$ & $5-48$ & $5-70$ \\
\hline
\end{tabular}

\subsubsection{Coarse Aggregate}

Locally available coarse aggregate was used in the research, round river gravel (maximum aggregate size $20 \mathrm{~mm}$ ). Their sieve analysis and grading were performed in accordance with (BS 812 : 1983), and given in table (4).

Table (4): Sieve Analysis of Coarse Aggregate

\begin{tabular}{|c|c|c|}
\hline Sieve Size $(\mathrm{mm})$ & Specification Limits & \% Passing of the Sample \\
\hline 37.5 & 100 & 100 \\
\hline 20 & $95-100$ & 97 \\
\hline 10 & $25-55$ & 40 \\
\hline 5 & $0-10$ & 0 \\
\hline
\end{tabular}




\subsection{Mix Proportions and Specimens Preparation}

Mix proportioning of the ingredients were designed using the current British Method (DOE). The aggregate were considered in (saturated surface dry) condition. Five mix proportions were prepared maintaining different cement content and (w/c). Details of the mixes are shown in table (5). Mix designations M1 to M5 are corresponding to the mix proportions. For each mix, cube specimens $(100 \times 100 \times 100) \mathrm{mm}$ were prepared in the laboratory according to (BS 1881: part 108:1983). Slumps of the fresh concrete mixes were measured in accordance to (BS 1881: part 102:1983), before the mix ingredients were cast into the molds. The samples kept in their molds for about $24 \mathrm{hr}$., then demolded, and subjected to two different curing conditions, moist cured and air cured for 28 days, table (5) shows the values of slump of the mixes used as well as the values of compressive strength under each curing condition.

Table (5): Details of Mix Proportions and Compressive Strength Results

\begin{tabular}{|c|c|c|c|c|c|}
\hline \multirow{2}{*}{$\begin{array}{c}\text { Mix } \\
\text { Designation }\end{array}$} & \multirow{2}{*}{$\begin{array}{c}\text { Cement } \\
\text { Content } \\
\left(\mathrm{kg} / \mathrm{m}^{3}\right)\end{array}$} & $\begin{array}{c}\text { Mix Proportion (by } \\
\text { weight })\end{array}$ & $\begin{array}{c}\text { Slump } \\
(\mathrm{mm})\end{array}$ & \multicolumn{2}{|c|}{$\begin{array}{c}\text { Compressive Strength } \\
\text { (MPa) }\end{array}$} \\
\cline { 5 - 6 } & & & $\begin{array}{c}\text { Moist } \\
\text { Cured }\end{array}$ & $\begin{array}{c}\text { Air } \\
\text { Cured }\end{array}$ \\
\hline $\mathrm{M}_{1}$ & 355 & $1: 2.12: 2.58 / 0.7$ & 230 & 17.4 & 11.7 \\
\hline $\mathrm{M}_{2}$ & 390 & $1: 1.92: 2.33 / 0.6$ & 190 & 26.1 & 16.6 \\
\hline $\mathrm{M}_{3}$ & 440 & $1: 1.71: 2.08 / 0.5$ & 110 & 33.7 & 26.6 \\
\hline $\mathrm{M}_{4}$ & 500 & $1: 1.50: 1.83 / 0.4$ & 80 & 40.5 & 36.8 \\
\hline $\mathrm{M}_{5}$ & 580 & $1: 1.30: 1.58 / 0.3$ & 20 & 48.6 & 43.1 \\
\hline
\end{tabular}

\subsection{Test Methods}

At the end of curing period, 3 specimens were tested for each concrete property. Compressive strength of the concrete specimens was tested according to (BS: 1881:part116:1983). Density, absorption, and volume of permeable voids (porosity) were tested and calculated according to ASTM (C 642-97) [14].

In this test, water absorption can only take place in pores, which were unoccupied during drying and filled with water during the immersion period. These pores can be considered as penetrable pores and therefore, the absorption of the concrete sample after immersion in water until saturation indicates its penetrability [15].

This boiling test is of importance since it determines percentage of water absorbed which reflects the amount of voids in concrete, and this would give an idea of concrete capability to retain water and its potential to corrode [16].

\section{Results and Discussions}

Comparing the values of compressive strength of the specimens, tested at 28 days after curing under two different regimes are shown in table (5) and fig.(1). It is apparent that the compressive strength of the moist cured specimens, exhibited better performance as compared to that of the air cured specimens. The development of good compressive strength for specimens under moist curing is credited to sufficient moisture, which maintained to continue the hydration of cement. This also indicated that the compressive strength of concrete not influenced by the overall water content but rather by moisture movement in the concrete specimens [6]. 


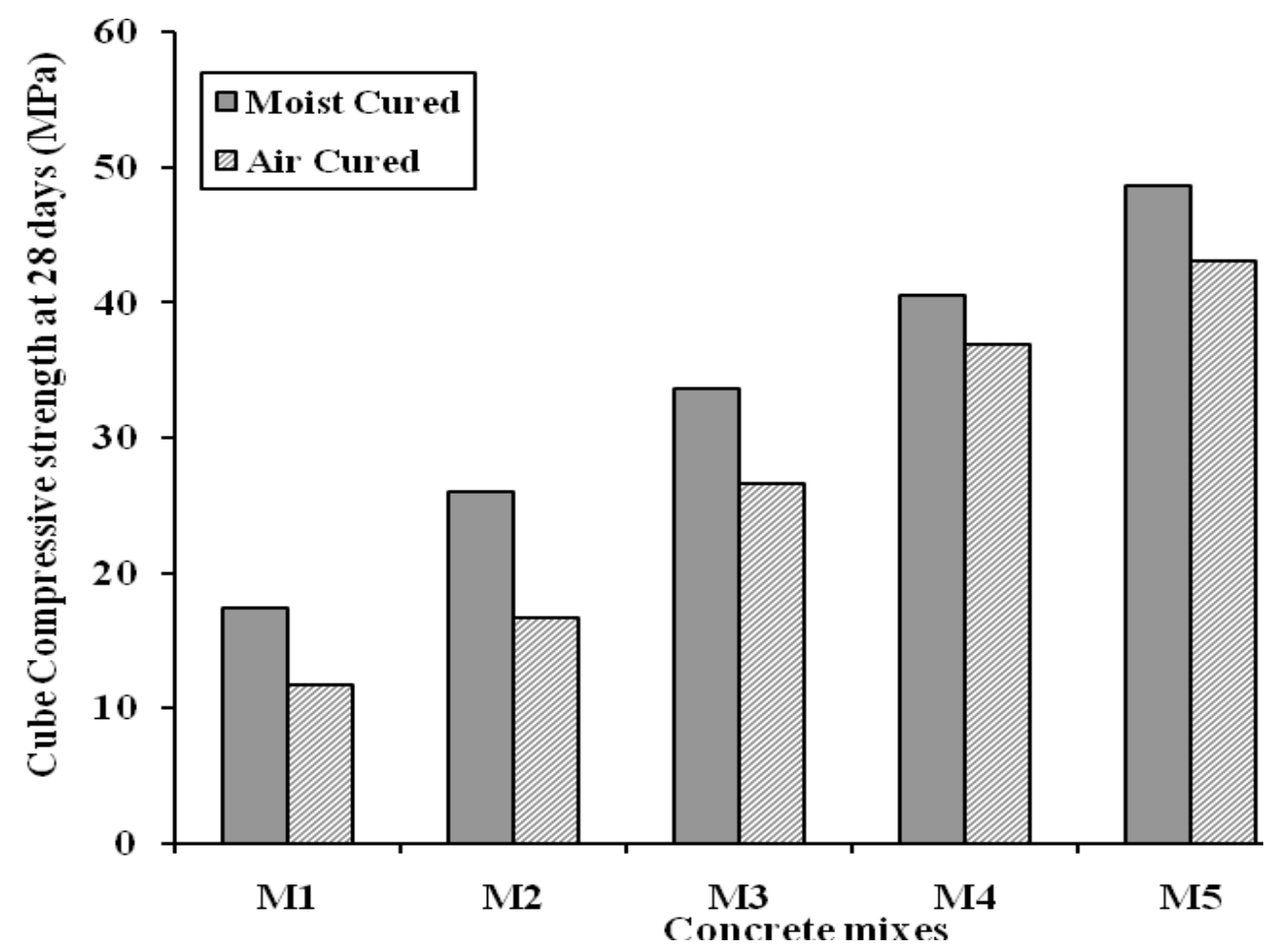

Fig. (1): Compressive strength at 28 days of concrete mixes for both curing conditions.

Fig.(1) shows the role of curing on the compressive strength of the concrete. Under an efficient curing method such as moist curing, the relative humidity is above $80 \%$, enabling the hydration of cement to continue. Conversely, the concrete specimens, water loss or moisture through evaporation and become dry in the absence of proper curing. When hydration stops, sufficient calcium silicate hydrate cannot develop from the reactions of cement compounds and water. Calcium silicate hydrate is the major strength providing reaction product of cement hydration. It also acts as a porosity reducer and thereby results in a dense microstructure in concrete. Therefore, an efficient curing is inevitable to prevent the moisture movement or evaporation of water from concrete surface. This can be accomplished by keeping the concrete element completely saturated or as much saturated as possible until the water-filled spaces are substantially reduced by hydration products [6].

Ultimately, the concrete can achieve higher strength and greater resistance to physical or chemical attacks in aggressive environments. Therefore, a suitable curing method is essential in order to produce strong and durable concrete [8]. A number of factors, such as amount of cement, amount of water, types of ingredients, mix proportions, curing, temperature, age, size and shape of specimen, and test conditions affect the compressive strength [17].

Fig.(2) shows to the rate of increase of compressive strength of specimens cured under the two regimes, with the increase in the quantity of cement for the concrete mixes. Also, the compressive strength decreases with increase in $(\mathrm{w} / \mathrm{c})$, this means that when the cement content is maintained constant and the amount of mixing water is increased, the strength decreases, this is explained by fig.(3) for both curing conditions. 


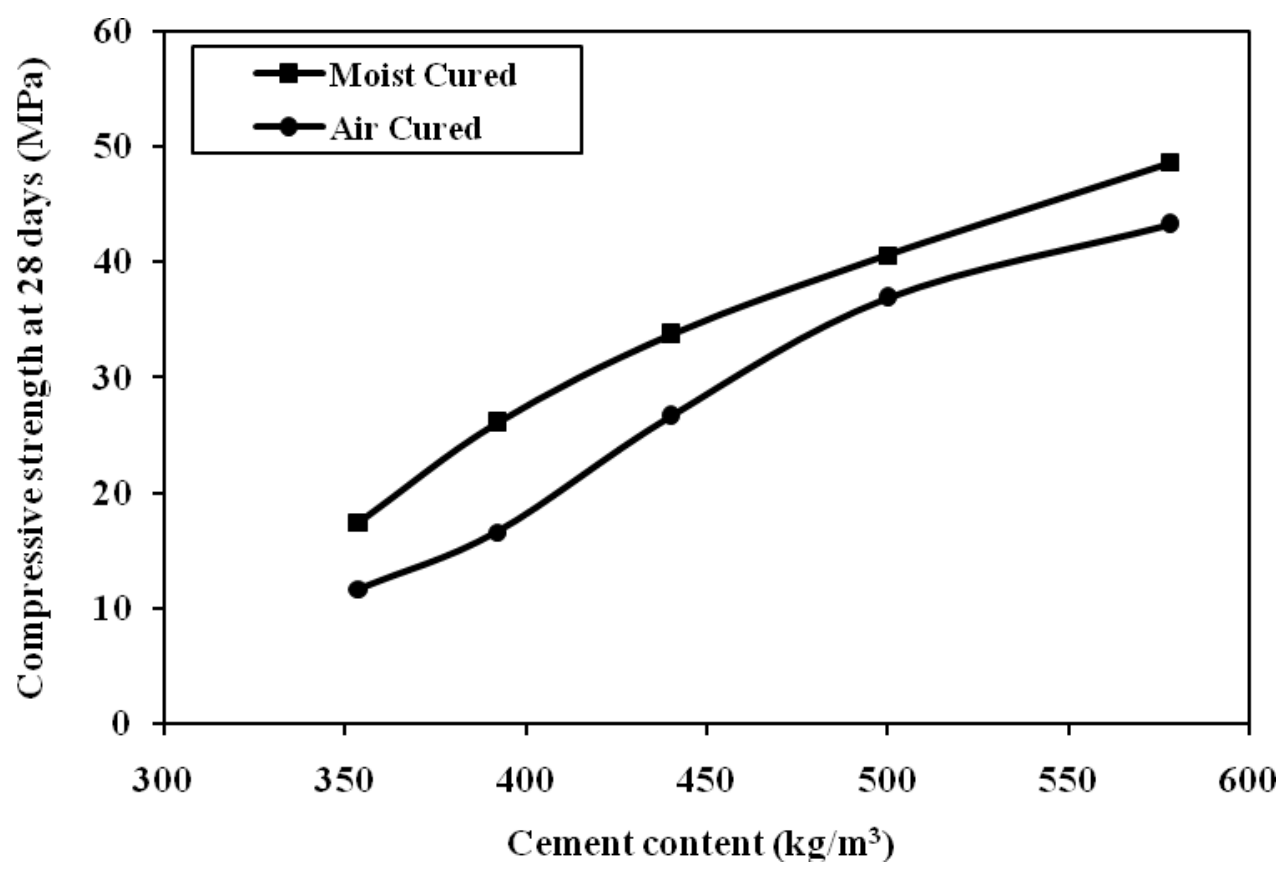

Fig. (2): Relationships between compressive strength at 28 days and cement content for both curing conditions

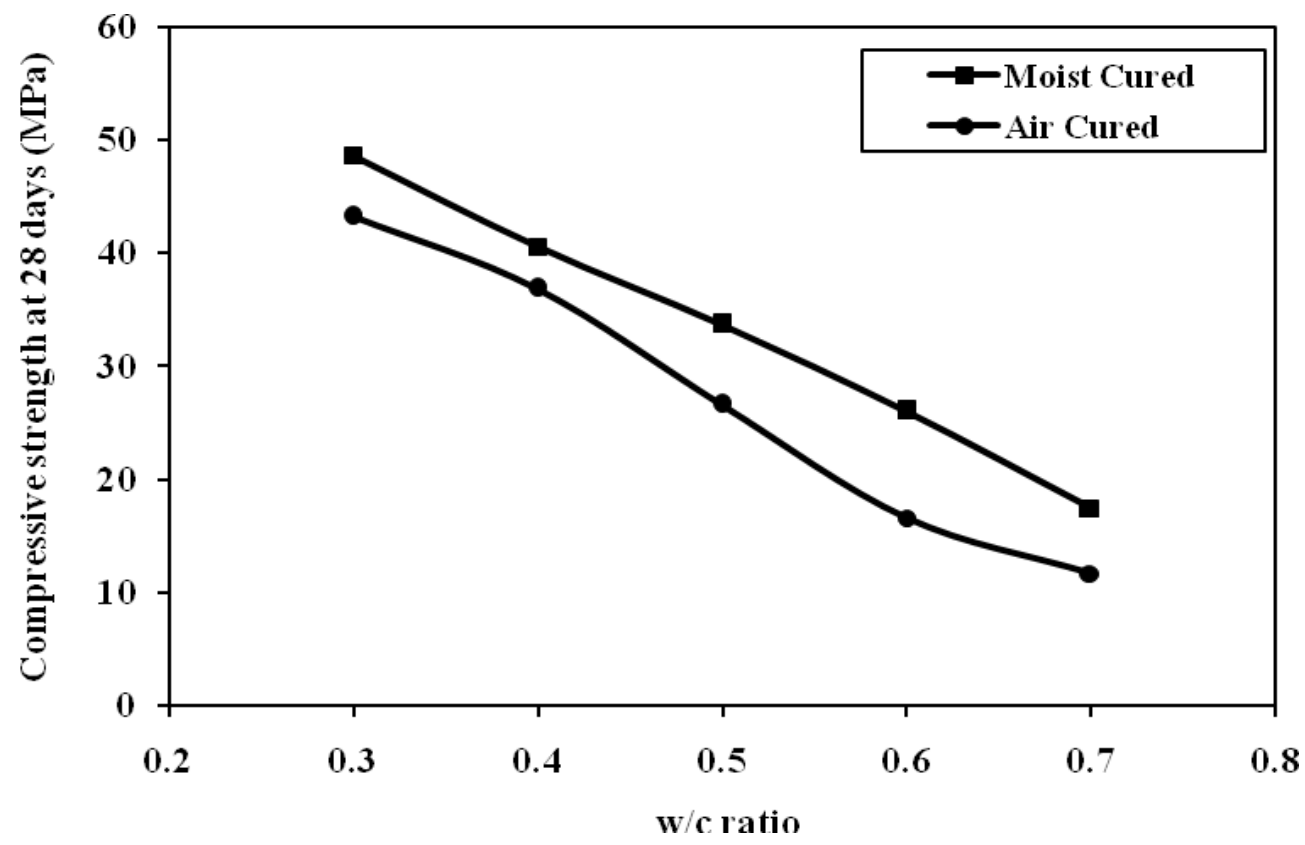

Fig. (3): Relationships between compressive strength at 28 days and (w/c) for both curing conditions.

Table (6) shows to the results of the boiling test (ASTM (C 642-97)) of the concrete specimens under the two regimes of curing. 
Abdul Kreem: Influence of Concrete Mix Proportions and Curing Regimes on Density,

Table (6): Results of Boiling Test for both Curing Regimes

\begin{tabular}{|c|c|c|c|c|c|c|c|}
\hline \multicolumn{8}{|c|}{ Results of Moist Cured Specimens } \\
\hline $\begin{array}{c}\text { Mix } \\
\text { Designation }\end{array}$ & $\begin{array}{l}\text { Absorption } \\
\text { after } \\
\text { Immersion } \\
(\%)\end{array}$ & $\begin{array}{c}\text { Absorption } \\
\text { after } \\
\text { Immersion \& } \\
\text { Boiling (\%) }\end{array}$ & $\begin{array}{c}\text { Bulk } \\
\text { Dry } \\
\text { Density } \\
\left(\mathrm{kg} / \mathrm{m}^{3}\right)\end{array}$ & $\begin{array}{c}\text { Bulk } \\
\text { Densityafter } \\
\text { Immersion } \\
\left(\mathrm{kg} / \mathrm{m}^{3}\right)\end{array}$ & $\begin{array}{c}\text { Bulk Density } \\
\text { after } \\
\text { Immersion \& } \\
\text { Boiling }\left(\mathrm{kg} / \mathrm{m}^{3}\right)\end{array}$ & $\begin{array}{l}\text { Apparent } \\
\text { Density } \\
\left(\mathrm{kg} / \mathrm{m}^{3}\right)\end{array}$ & $\begin{array}{c}\text { Volume of } \\
\text { Permeable } \\
\text { Voids Pore } \\
\text { Space, } \\
\text { Porosity(\%) }\end{array}$ \\
\hline $\mathrm{M}_{1}$ & 5.37 & 5.51 & 2233 & 2353 & 2356 & 2546 & 12.3 \\
\hline $\mathrm{M}_{2}$ & 4.63 & 4.76 & 2352 & 2461 & 2464 & 2648 & 11.2 \\
\hline $\mathrm{M}_{3}$ & 4.16 & 4.29 & 2449 & 2551 & 2554 & 2736 & 10.5 \\
\hline $\mathrm{M}_{4}$ & 3.73 & 3.84 & 2496 & 2589 & 2592 & 2761 & 9.6 \\
\hline $\mathrm{M}_{5}$ & 3.30 & 3.42 & 2514 & 2597 & 2600 & 2750 & 8.6 \\
\hline \multicolumn{8}{|c|}{ Results of Air Cured Specimens } \\
\hline $\mathbf{M}_{1}$ & 6.99 & 7.09 & 2187 & 2340 & 2342 & 2588 & 15.5 \\
\hline $\mathrm{M}_{2}$ & 5.65 & 5.78 & 2283 & 2412 & 2415 & 2630 & 13.2 \\
\hline $\mathrm{M}_{3}$ & 5.21 & 5.33 & 2361 & 2484 & 2487 & 2701 & 12.6 \\
\hline $\mathrm{M}_{4}$ & 4.58 & 4.74 & 2402 & 2512 & 2516 & 2711 & 11.4 \\
\hline $\mathrm{M}_{5}$ & 4.14 & 4.26 & 2486 & 2589 & 2592 & 2780 & 10.6 \\
\hline
\end{tabular}

From table (6), the results of bulk density indicates that an increase in (w/c), leads to a decrease in bulk density. An increase in (w/c) implies a decrease in cement content and an increase in water content, this reduces the overall weight of the concrete. Increased cement content, another factor, is seen to have an increase in the bulk dry density and bulk density after immersion and boiling of the concrete, since it has the highest specific gravity among concrete ingredients. It is also apparent from table (6) that the moist cured specimens showed more density than the air cured specimens. This is due to the fact that moist cured specimens become saturated and causing the production of more $(\mathrm{C}-\mathrm{S}-\mathrm{H})$ gel which also contributes to the increase the bulk density [18].

The water absorption has emerged as the most useful parameters explaining the moisture dynamics of concrete. The water absorption mainly depends on the total volume of pores (porosity) [19].

From table (6), it was observed that a reduction of the water absorption was accomplished with a reduction in $(\mathrm{w} / \mathrm{c})$, this is evident in both concrete specimens cured differently. The results indicated that the water absorption increases with an increase in water content of the mixes, besides, it was also indicated that the water absorption was much affected by the extra water added into the mixture since it increases capillary porosity of concrete. However, a relatively higher (w/c) produces a weaker and previous matrix, leading to higher capillary porosity that is turn responsible for the increase in water absorption [20].

The cement content of the concrete mixes has a particularly strong effect on the water absorption properties of concrete specimens, although the water absorption values are, in both cases, reduced with an increase of cement quantity which consequently enhancing the durability of concrete. 
Concrete mixes which records higher absorption is due to the porous nature of the mix itself, this creates internal network or path way that allows the flow of water into the concrete [21].

From the durability point of view, it was found that the durability of concrete was very much affected by the curing condition. At moist cured, concrete specimens give better durability performance that represented by the values of absorption after immersion and absorption after immersion and boiling which were less than the state of air cured. As well as, the durability behavior can be explained by the relationship between the compressive strength and water absorption, also the relationship between bulk dry density and water absorption in figs.(4) and (5), respectively.

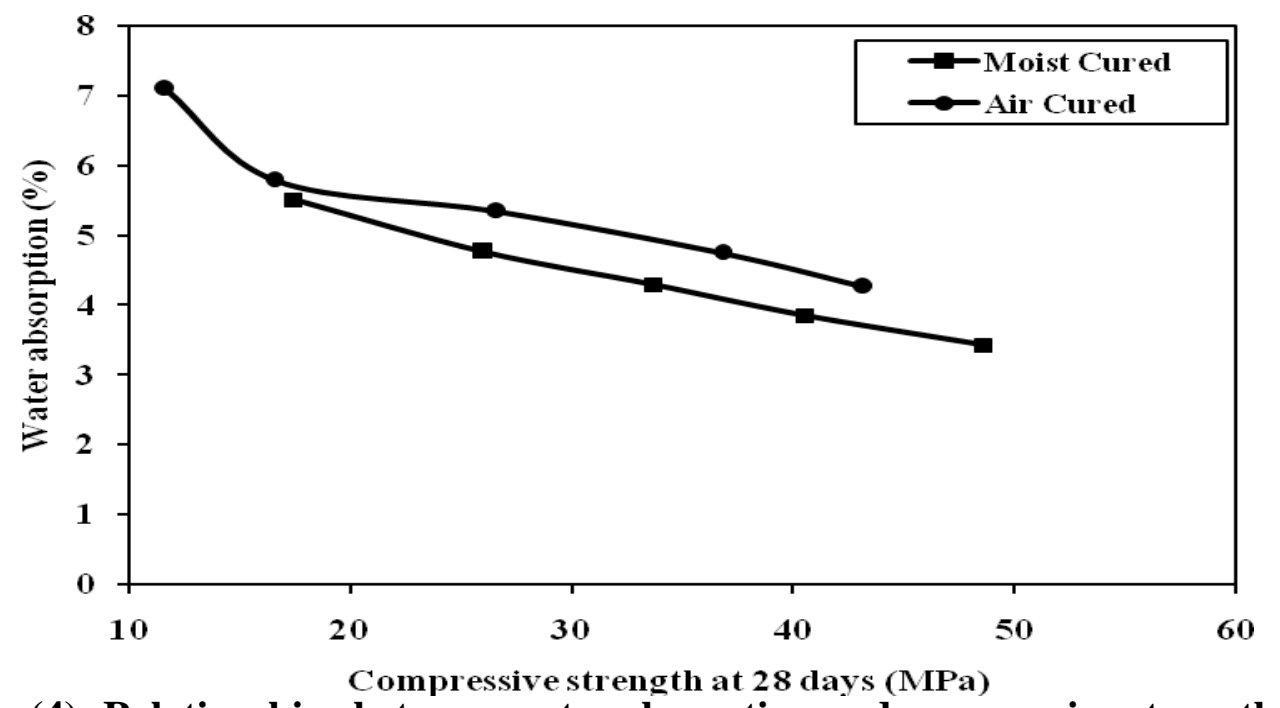

Fig. (4): Relationships between water absorption and compressive strength at 28 days for both curing conditions.

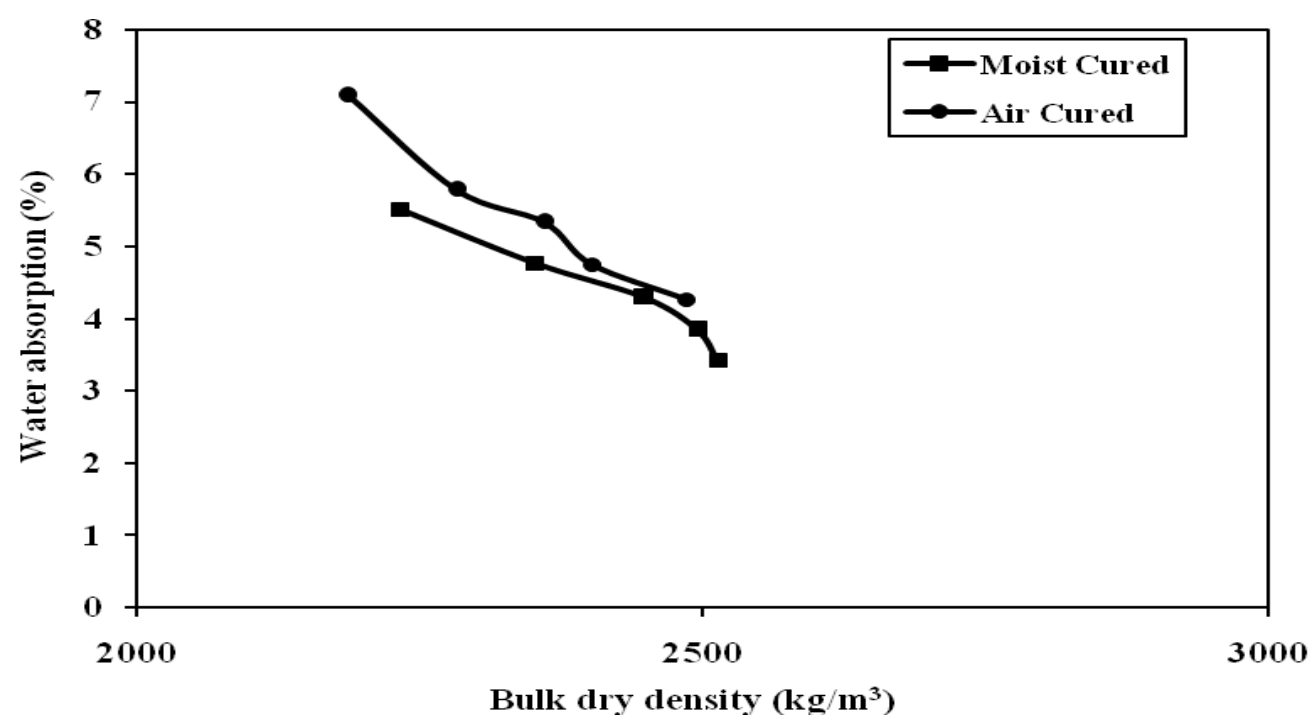

Fig. (5): Relationships between water absorption and the bulk dry density for both curing conditions. 
In the procedure of the absorption test, the drying operation withdraws not only the mechanically suspended water but also some of the colloidal water more tenaciously held in the cement gel. Hence the absorptions, or porosities indicated by the absorptions, are larger than for the usual temperature-humidity environment of the concrete [2].

The porosity obtained in the boiling test is the volume of permeable voids in the concrete. This volume is a method of determining the water absorption after immersion in water at room temperature, after immersion and boiling, and the "volume of permeable voids (VPV)" or volume of water absorption after a period in boiling water of a hardened concrete sample. The high temperature affects both the viscosity and the mobility of the water molecules which may enable the greater displacement of pore system within the hardened concrete. This is shown in the relationship between absorption and the absorption after boiling in fig.(6) [4].

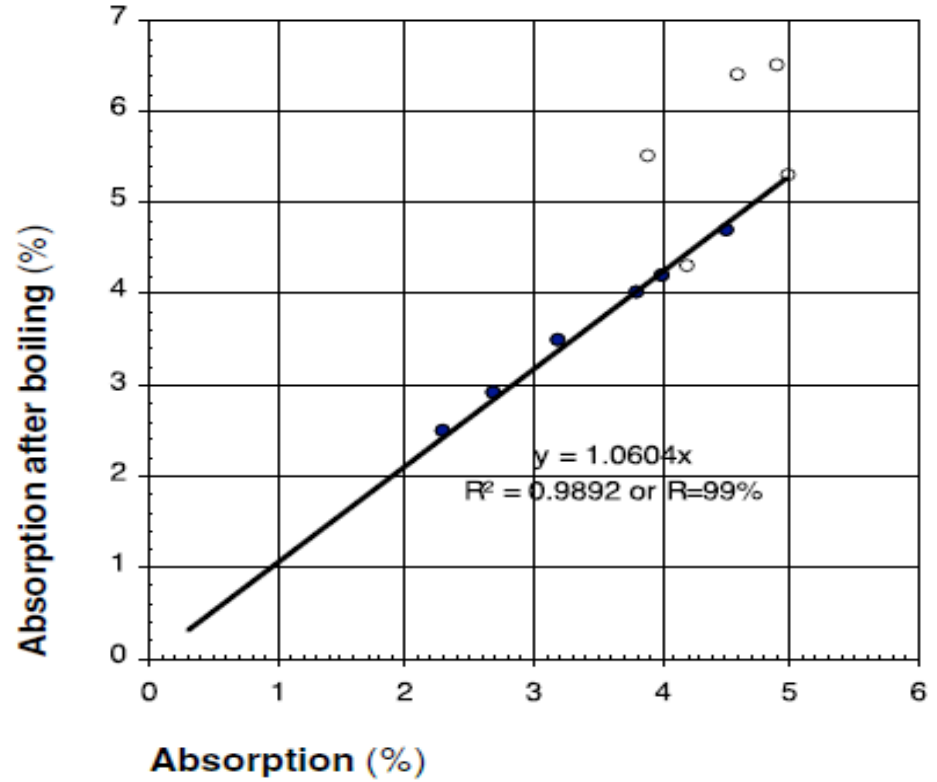

Fig. (6): Effect of boiling on absorption [4].

Table (6) shows the volume of permeable voids, (i.e. pores containing evaporable water) obtained from the water absorption tests. This volume as appeared roughly corresponds to the total capillary porosity and as table (6) indicates, it decrease with the advance of cement hydration and lowering of $(w / c)$ in the two regimes of curing.

The porosity of concrete is determined by [4]:

1. type of cement and other mix constituents;

2. concrete mix proportions;

3. compaction and curing.

The porosity of concrete is highly dependent on the (w/c) and (aggregate/cement) ratios whereas the type and amount of cement affect the pore size distribution and chemical binding capacity of the concrete. Both strength and transport characteristics are linked to the pore structure of the concrete. Concrete with low porosity usually has high strength and high resistance to the penetration of aggressive ions [4].

An increase in water content increases the voids in concrete, which decreases the durability, watertightness, and of course the compressive strength. Early theories on concrete strength have established a relationship between compressive strength and void content and the void/cement ratio. These relationships are similar to the compressive strength $/(\mathrm{w} / \mathrm{c})$ relationship, and stress the importance of cement content and low void content in achieving good performance concrete. Thus it should be understood that good dense concrete requires a sufficient amount of cement plus properly graded aggregates to reduce the void content [17]. The water content should be enough to guarantee complete hydration of Portland cement. Any excess water added to the mix increases the void content, which in turn decreases the quality of concrete. But it should be recognized that insufficient amount of cement means an 
inadequate amount of binder, and the resulting concrete is definitely of lower quality. In summary, although the $(\mathrm{w} / \mathrm{c})$ is a convenient way to design the mix, good quality concrete requires a sufficient amount of water, well-graded aggregates, and a minimum amount of mixing water [4]. This can be represented by the relationship between compressive strength and porosity in fig.(7), besides the relationship between porosity and (w/c) in fig.(8).

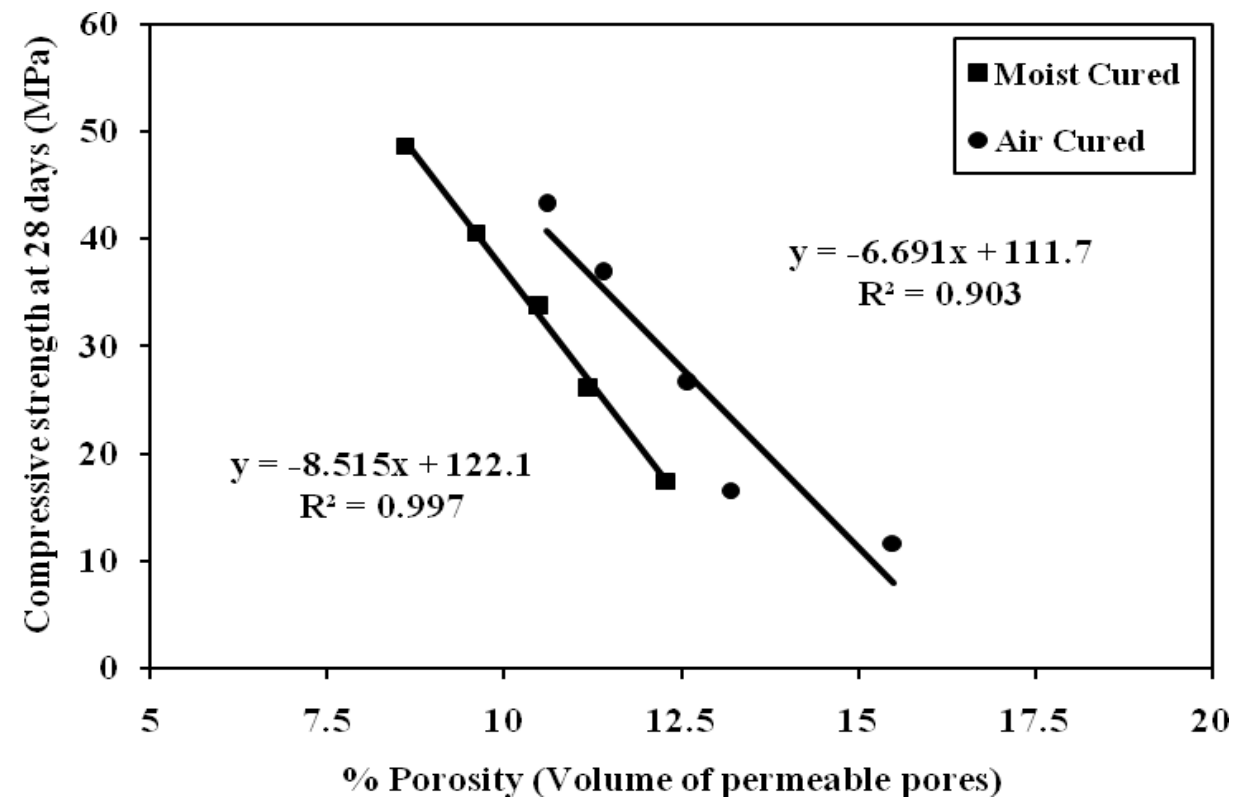

Fig. (7): Relationships between compressive strength at 28 days and porosity (volume of permeable pores) for both curing conditions.

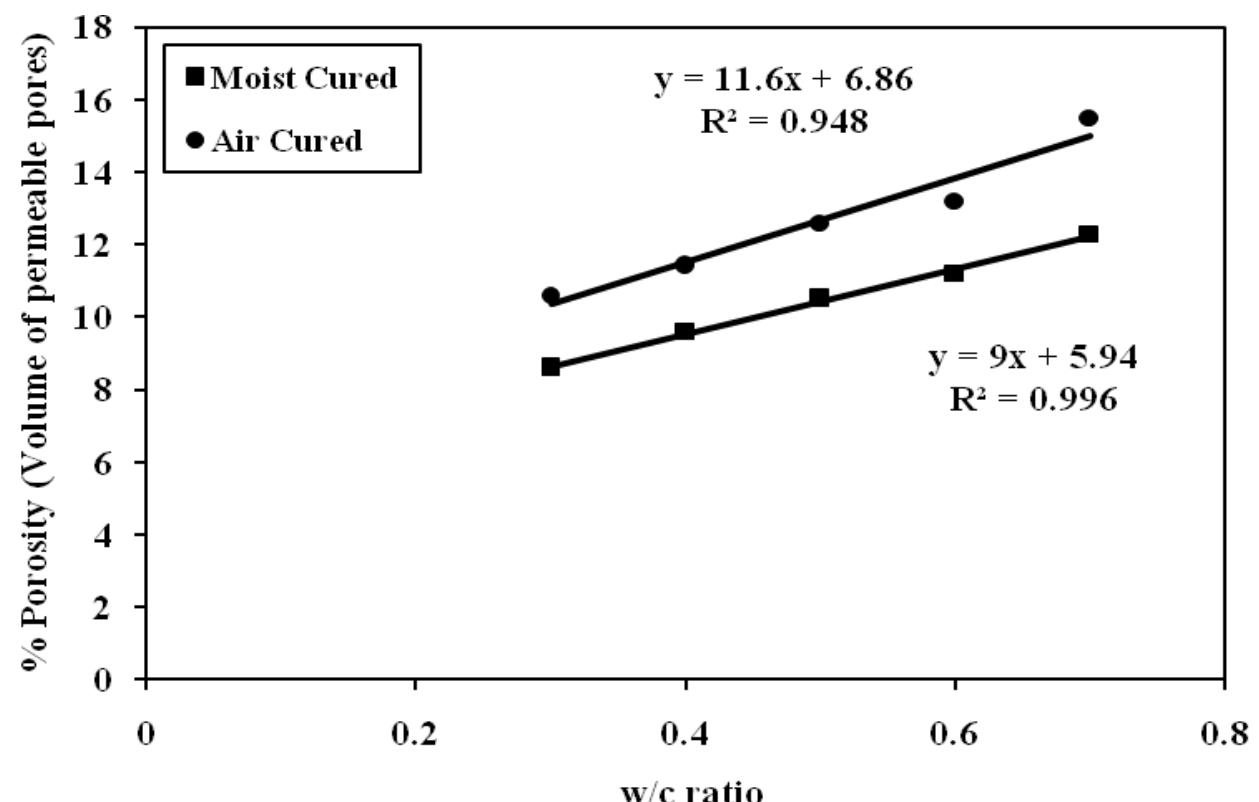

Fig. (8): Relationships between porosity (volume of permeable pores) and (w/c) for both curing conditions.

Schaefer et al. found a linear relationship between the compressive strength and the void ratio, and according to this correlation, the low void content leads to the high compressive strength. They also developed a relationship between compressive strength and void content as shown in equation (1) [22]: 


\section{Compressive Strength $(\mathrm{MPa})=4762.1-97.16 \times[$ void ratio $(\%)]$}

It was observed that the bulk density decreased with an increase in porosity, fig.(9) explained that. At 28 days, for the moist cured specimens, the porosity (volume of permeable voids) lower compared to air cured specimens, thus the water permeability is lower. As well as it was observed that there was a noticeable difference between the porosity of the air cured specimens and the moist cured specimens. This shows when sufficient amount of water is present, the hydration of cement can continue.

Consequently, the total porosity of the concrete is reduced as the probability of pores being either blocked or narrowed down by continued formation of hydration products are increased [23]. This fact is also confirmed by other researchers who reported that the duration and quality of curing of the fresh mix determine the process of hydration and the volume of hydration products, which may eventually fill the capillary pores and reduce their permeability [13].

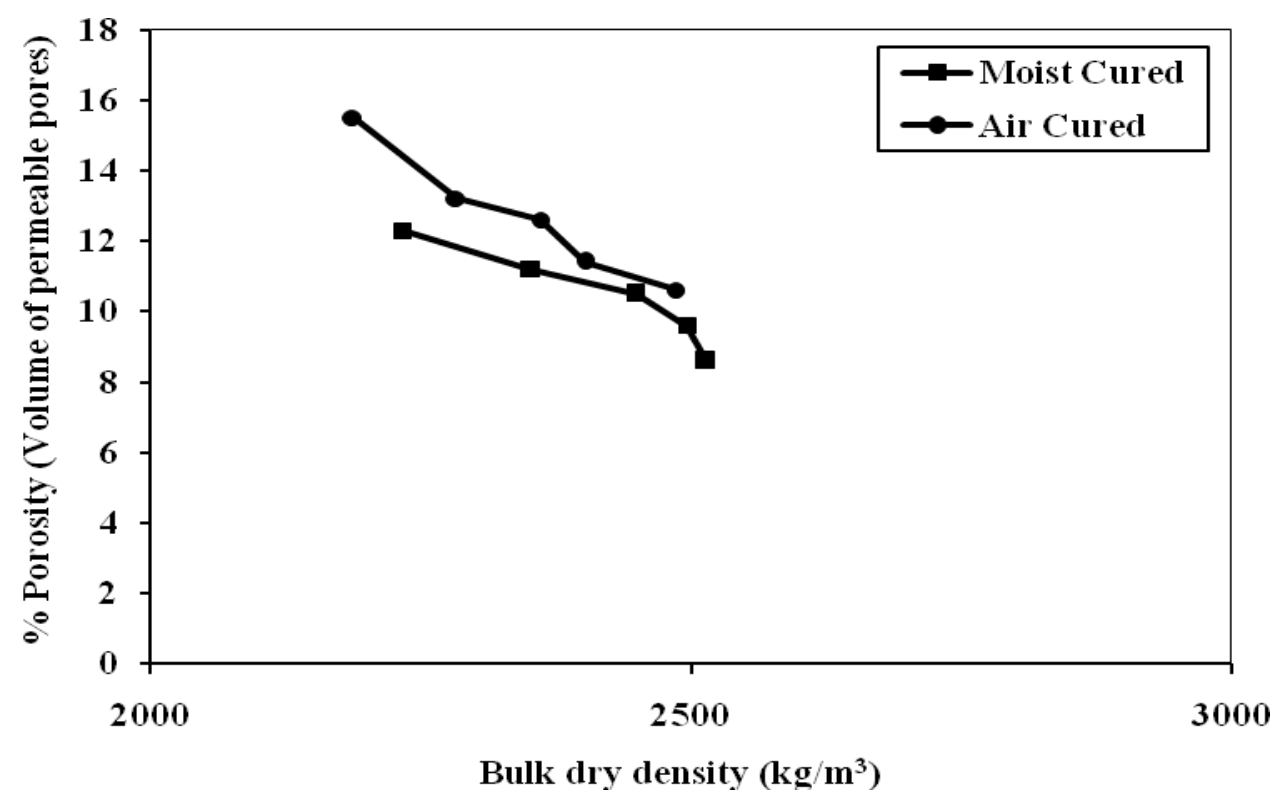

Fig. (9): Relationships between porosity (volume of permeable pores) and bulk dry density for both curing conditions

Below 95\% relative humidity it is believed that the rate of hydration will be slowed to the extent that no further reduction in large porosity will occur even though hydration itself will not actually cease until $80 \%$ relative humidity. This is significant as both strength and durability are related to porosity, with large porosity having a particularly large influence on durability [24].

\section{Conclusions} can be drawn:

On the basis of the experimental investigation carried out, the following conclusions

1) Concrete mix proportion parameters such as the amount of cement and the (w/c), impact strongly on the mechanical strength and the durability performance of the final products.

2) Curing conditions play a major role in the physical and mechanical properties of the concrete. Relatively small changes in the overall moisture content of hardened concrete produced considerable changes in the physical characteristics and mechanical strength. This 
indicated that an assuming adequate hydration, the method of curing influences concrete behavior not so much through the overall moisture content, but rather the moisture distribution (gradient) in the concrete.

3) From the results, it can be seen that durability is more related to $(w / c)$ than compressive strength. As the water content reduces, the paste content grows reducing the volume of capillary pores and thus showed a reducing trend of water absorption as well as porosity as a volume of permeable voids, in addition the bulk density increases.

4) From the relationship between the bulk dry density and porosity values, it was observed as the density decrease due to the increase of strength, and the hydration, as a result, the porosity increased.

5) A good correlation was also observed between the (w/c) and the porosity values, i.e. the $(\mathrm{w} / \mathrm{c})$ increase considerably with the increase of porosity.

6) From the relationship between compressive strength and porosity, a good correlation was also observed, it was shown that the reduction in porosity leads to rise in the compressive strength of the concrete, this is similar to the relationship between the water absorption and compressive strength, consequently the relationship between the water absorption and the bulk density.

\section{References}

[1] Mamlouk, M.S. and Zaniewski, J.P., "Materials for Civil and Construction Engineers", Addison Wesley Longman, Inc., California, 1999.

[2] Troxell, G.E., Davis, H.E. and Kelly, J.W., "Compostion and Properties of Concrete", McGrew-Hill, Inc., USA, 1968.

[3] Kosmatka, S.H., Kerkhoff, B. and Panarese, W.C., "Design and Control of Concrete Mixtures", Portland Cement Association, USA, 2003.

[4] Cement Concrete and Aggregate Australian, "Chloride Resistance of Concrete", www.ccaa.com.au, June, 2009, 37pps.

[5] Lamond, J.F. and Pielert, J.H., "Significance of Tests and Properties of Concrete and Concrete-Making Materials", ASTM International, ASTM Stock No.: STP169D, USA, 2006.

[6] Aminur, M.R., Harunur, M.R., Teo, D.C.L. and Abu Zakir, M.M.,"Effect of Aggregate and Curing Conditions on the Compressive Strength of Concrete with Age", UNIMAS e-Journal of Civil Engineering, Vol.1, Issue 2, April, 2010, pp.1-6.

[7] Jana, D., "Concrete Scaling-A Critical Review", Proceeding to the $29^{\text {th }}$ Coference on Cement Microscopy Quebec City, Canada, May 20-24, 2007, pp.91-130.

[8] Baker, A.F., "Durability of Concrete Structures: Investigation, Repair, Protection", E \& FN Spon, 1992.

[9] Perera, A.S.R., Al-Tabbaa, A., Reid, J.M. and Stegemann, J.A., "Stabilization/Solidification/Treatment and Remediation Part IV: Testing \& performance Criteria", State of Practice Report UK, 2003, pp.1-23.

[10] Teo, D.C.L., Mannan, M.A. and Kurian, V.J., "Durabilty of Lightweight OPS Concrete Under Different Curing Conditions", Materials and Structures (2010) 43, pp.1-13.

[11] Neviile, A.M., "Properties of Concrete", Peourson Education Ltd, England, 2002.

[12] Khan, M.I., "A Novel Method for Measuring Porosity of High Strength Concrete", Proceedings in the $7^{\text {th }}$ Saudi Engineering Conference, KSU, Riyadh, 2007, pp.49-61.

[13] Miloud, B., "Permeability and Porosity Charecteristics of Steel Fiber Reinforced Concrete", Asian Journal of Civil Engineering (Building and Housing), Vol.6, No.4, 2005, pp.317-30. 
Abdul Kreem: Influence of Concrete Mix Proportions and Curing Regimes on Density,

[14] ASTM (C 642.1997): "Standard Test Method for Density, Absorption, and Voids in Hardened Concrete", Annual Book of ASTM Standards: American Society for Testing and Materials.

[15] Sahraman, M. and Li, V.C., "Influence of Microcracking on Water Absorption and Sorptivity of ECC", Materials and Structures (2009) 42, pp.593-603.

[16] Alenezi, N., "Evaluation and Assesment of Concrete Produced by Utilizing of Treated Wastewater", Proceedings in Concrete Sustainability Conference, Kuwait, 2010, pp.1-9.

[17] Somayaji, S., "Civil Engineering Materials", Prentice Hall, Inc., New Jersey, 1995.

[18] Memon, N.A., Sumadi, S.R. and Ramli, M., "Lightweight Aerated Concrete Incorporating Various Percentages of Slag and PFA", Journal of Applied Sciences, Vol.6, No.7, 2006, pp.1560-1565.

[19] Nambiar, E.K.K. and Ramamurthy, K., "Sorption Charecteristics of Foam Concrete", Cement and Concrete Research 37, 2007, pp.1341-1347.

[20] Olivia, M., Sarker, P. and Nikraz, H., "Water Penetrability of Low Calcium Fly Ash Geopolymer Concrete", ICCBT 2008-A-(46), pp.517-530.

[21] Hassan, A.H., Al-Mattarneh, H.M.A., Abdullahi, M., Abu Hassan, M.H., Mohammed, B.S. and Mustafa, K.N., " Compressive Strength and Absorption of Concrete Composed of Natural and Palm Oil Clinker (POC) Aggregates", ICCBT 2008-A-(07), pp.93-100.

[22] Schaefer, V.R., et al., "Mix design development for pervious concrete in cold weather climates", National Concrete Pavement Technology Centre, 2006, p.83. [23] Teo, D.C.L., Mannan, M.A., Kurian, V.J. and Ganapathy, C., "Lightweight Concrete Made From Oil Palm Shell (OPS): Structural Bond and Durability Properties", Building and Environment 42, 2007, pp.2614-2621.

[24] Newman, J. and Choo, B.S., "Advanced Concrete Technology, Concrete Properties", Replika Press Pvt Ltd, India, 2003.

The work was carried out at the college of Engineering. University of Mosul 